\title{
Knowledge, Belief and Attitude of the Community towards Leprosy Patients in Gindeberet Woreda, West Shewa Zone
}

\author{
Atinkut $\mathrm{Z}^{1 *}$, Muna $\mathrm{S}^{2}$ and Tesema $\mathrm{A}^{1}$ \\ ${ }^{1}$ Department of Psychology, Ambo University, Ambo, Ethiopia \\ ${ }^{2}$ Department of Early Childhood Care and Education, Ambo University, Ethiopia
}

*Corresponding author: Atinkut Zewdu, Department of Psychology, Ambo

Research Article

Volume 2 Issue 4

Received Date: July 09, 2018

Published Date: August 01, 2018

University, Pobox 19, Ethiopia, Tel: +251918776324; Email: atinkutpsycho09@gmail.com

\section{Abstract}

Leprosy is a chronic infectious disease of public health importance and one of the leading causes of permanent physical disability. Nevertheless, the drop in prevalence following multidrug therapy has resulted in the neglect of leprosy. The prevalence and annual incidence of new cases of leprosy is persistently high for the past 10 years in Ethiopia. The purpose of this study was to examine the knowledge, belief and attitude of the community towards leprosy patients in Gindeberet Woreda, Oromia region, Ethiopia. A community based cross sectional survey design was carried out on a sample of 571 randomly selected adults. A self-administered structured questionnaire was used to collect the data. Descriptive statistics, independent sample t-test, one-way ANOVA, point bi-serial and Chi-square were utilized to analyze the collected data. As a result, 453 (79.3\%) and 351 (61.5\%) of respondents had poor knowledge and negative attitude towards leprosy respectively. More specifically, 263 (48.7\%) of the respondents correctly believed that leprosy was caused by germs. However, 431 (75.5\%), 413 (72.3\%), 355(62.2\%), 333 (58.3\%) and 275 (48.1\%) of respondents were attributed vitamin deficiency, unclean environment, impure blood, eating too much cooling food and hereditary as the causes of leprosy while only $14 \%$ and 10.5\% 10.5\% believed that leprosy was a punishment for sins/curse and evil spirits respectively. Hence, nearly half of respondents stated that leprosy could be transmitted from mother to infant and personal contact. Also, 140(24.5\%) correctly reported that leprosy could be treated with anti-leprosy drugs. In fact, 107 (36.15\%) did not want to sit with leprosy patients. Besides, 67\% of the respondents were not able to list down the cardinal signs of leprosy correctly and 71\% didn't know the patho-physiology of disability in leprosy. In this study, the level of leprosy knowledge was associated with the sex, age, educational status, and religion of respondents. Moreover, sex, age and educational status had statistically significant effect on respondents' attitude towards leprosy. In addition, among all examined variables, only sex and educational status had an interaction effect on respondents' attitude towards leprosy. Strong positive correlation was observed between the knowledge and attitudes of the community towards leprosy patients. In conclusion, an overall lack of knowledge and prevalence of delusion regarding the cause, transmission and outcome of leprosy was identified among the community. Stigmatizing attitudes towards leprosy 
patients were also observed. Therefore, there is a need to educate the community in order to alleviate the stigma and promote positive attitude towards leprosy.

Keywords: Leprosy; Knowledge; Beliefs; Attitude

Abbreviations: MDT: Multidrug therapy; PB: Paucibacillary; SPSS: Statistical Package for Social Science.

\section{Introduction}

Leprosy is a disease caused by a Bactria called Mycobacterium Leprae. It is an acid-fast and rodshaped bacillus. The incubation period of Mycobacterium Leprae is very slow and it may take about five years. The disease mainly affects the skin, the peripheral nerves, mucosa of the upper respiratory tract and also the eyes, apart from some other structures. Untreated, leprosy can cause progressive and permanent damage to the skin, nerves, limbs and eyes [1]. Leprosy is a social disease that has left behind terrifying images of memory of mutilation, rejection and exclusion from society. It leads to progressive physical, psychological and social disabilities because of the stigma associated with the disease. Many people in developing countries have difficulties in accepting the disease due to misconceptions, stigma and superstitions they have towards the disease. This makes them reluctant to go to clinics for examination even after being diagnosed [1].

The current prevalence of leprosy is in the range of 5$10 / 10.000$ population in many endemic regions. As estimated in 1997, there were 1.15 million leprosy cases in the world. About 500.000 new cases were detected each year and about 2.1 billion people live in countries where the disease prevalence is more than $1 / 10.000$ people. More than 1 million people worldwide are irreversibly disabled due to the disease [2]. The signs of leprosy are mostly observed on the skin of affected individual [3]. The symptoms include a skin patch or patches with a definite loss of sensation and the patches can be pale or reddish or copper-colored, flat or raised. These patches do not itch, usually do not hurt and patients could experience lack sensation to heat, touch or pain and it can appear anywhere. Other signs of leprosy may include reddish or skin-colored nodules or smooth, shiny diffuse thickening of the skin without a loss of sensation [4]. Leprosy is thought to be transmitted via droplets from the nose and mouth during close prolonged contact with affected individuals, though the exact route of transmission has yet to be proven definitively [1].
Mostly, infections and bad blood are the dominant perceived causes of leprosy as identified by majority of leprosy patients and non-leprosy community members.

Leprosy can be cured with early diagnosis and treatment with multidrug therapy (MDT). Despite its curability, leprosy is one of the infectious diseases that are associated with stigmatized attitudes. The knowledge about how leprosy is caused, what kinds of symptoms it has and the knowledge towards the transmission of leprosy could be one of the important factor that has important for having a stigmatized attitude towards leprosy. In 1981, the WHO recommended multiple drug therapy (MDT). The introduction and expansion of MDT has dramatically decreased the prevalence of leprosy in all endemic countries. Drug treatment regimens recommended by WHO for Paucibacillary (PB) leprosy for 6 month are Dapsone and rifampicin while regimens for multibacillarv (ME) leprosy are dapsone, rifampicin and clofazimine for 12 months [5].

According to the study of Bekri, et al. [6], a high level of stigma associated with the disease and patients had high level of reliance on traditional healers. On the same study, low percent of patients (19\%) knew that leprosy was curable while majority of them believed heredity as the commonly believed cause of leprosy (84\%). In addition, regarding the symptoms of leprosy, participants believed that loss of body parts or deformities is the first. These issues could be related with the stigmatizing attitude by the community towards the diseases and these stigmatizing attitudes could be an obstacle for early identification and treatment of the case. In addition, because individuals infected by leprosy could be discriminated the society, it may have another psychosocial impact on them.

Overall, studies have found that the community knowledge of leprosy in the world was poor. For instance, a study in India Shetty, et al. [7] revealed that just $15 \%$ of the community was aware of the early signs of leprosy and very few (7 \%) knew that leprosy was caused by germs. The spread of the disease was rightly attributed to prolonged close contact by only $19 \%$ of the community respondents. An adequate knowledge of leprosy plays a 


\section{Nursing \& Healthcare International Journal}

large part in determining the community's health-seeking behavior. The lack of knowledge of leprosy among leprosy patients in India was highlighted in a study conducted by Pal, et al. [8] who found that overall only $8.5 \%$ knew the cause of the disease.

Communities over wide geographical and cultural backgrounds around the world harbor false beliefs and misconceptions regarding the cause and transmission of leprosy. Even though scientific knowledge and medical treatment have made advances in curing the disease and minimizing infectivity, these beliefs have persisted over the decades, nurturing the negative attitudes and the stigma attached to the disease. A study conducted in Malaysia among three major ethnic groups found that the Chinese held the most misconceptions, whereas the Malays had the least misconceptions regarding leprosy [9]. Most Chinese believed that sexual relations with prostitutes (41.2\%) and heredity (32.5\%) caused leprosy whereas the Iban community believed that heredity $(41.8 \%)$ was the predominant cause.

Leprosy is referred to as 'ngara' or 'lepero' in Botswana implying an association with "bad blood" [10] and as 'qumtina' in Ethiopia denoting the "state of amputation or mutilation" [11]. In Ethiopia TekleHaimanot, et al. [11], a significant number of people believed that leprosy was hereditary (48\%) and contagious (53\%). The societal beliefs on the causation of leprosy were also shared by the leprosy patients in Africa. Most patients in Ethiopia (84\%) believed that leprosy was hereditary [6] and in Nigeria, $58 \%$ attributed leprosy to the ingestion of certain foods, witchcraft and evil spirits [12]. Along with this, the widely held belief that leprosy is highly contagious and the intense stigma attached to the disease prompted the segregation of the leprosy patients to prevent the spread of the disease. In spite of current evidence that leprosy was curable and not contagious, public attitude towards leprosy has remained largely unchanged. Therefore, the diagnosis of leprosy can often be traumatic for individuals and their families and a person affected by leprosy suffers negative reactions such as shame, fear and guilt. The community reaction to leprosy cause serious constraints on social activities of the leprosy patient and their families $[13,14]$.

Leprosy has deep rooted stigma in the society; it is absurdly feared and caused migration of thousands of Ethiopian leaving behind their beloved ones and birth places. The society holds misconception that it is hereditary, calamity of God, curse etc. This exposed persons affected by leprosy to loss of social dignity, absence of self-confidence and self-disregard. As an instance, marriage between a family member of persons affected by leprosy and the members of the other communities is hardly possible to this day as well. Hence, Begging has been accepted by the Leprosy affected themselves and the society, even in religious holidays, as proper other than encouraging provision of decent employment. So begging has been the source of their income for many families [15]. Children hate to go far from their settlements for education due to fear of ridicule by their peers at school. Even if they travel to far institutions they do not mention their villages rather prefer to hide their address. Persons affected by leprosy were also victims of the societies' misconception about the disease and themselves. This inhibited them not to go to hospital but follow traditional means like Healers, Sorcerers, Holy water, using soil given by priests in monasteries. Before Multiple Drug Therapy treatment was taken for life long and people interrupt taking the medicine and engaged in labor works that aggravated disability profoundly [16].

Regarding to the study area, Gindeberet woreda is one of West Shewa Zone in the Oromia region of Ethiopia. Among 40 settlement sites in Ethiopia, Mukedima settlement in Gindeberet (Kachise) woreda in Oromia region is one of the most known and highly populated with leprosy in which over 200 persons affected by leprosy and more than 1000 family members are inhabited in these area. Researchers observed that these people have been systematically underestimated, marginalized and excluded by the given society, for this reason the researchers initiated to assess the knowledge, belief and attitude of the community towards leprosy patients.

\section{Materials and Methods}

\section{Study Design}

The purpose of the present study was to assess the knowledge, belief and attitude of the community towards leprosy patients in Gindeberet Woreda. To achieve this, Community based cross-sectional survey research design was used and data were collected and analyzed largely quantitatively with some qualitative descriptions.

\section{Sampling and Sample Size Determination}

The target population of this study was all community members in individual households found in Gindeberet area. Respondents were 615 community members randomly selected from all kebeles. Also, 5\% of respondents were also added for non- response rate. However, data collectors could collect 571 correctly filled 


\section{Nursing \& Healthcare International Journal}

questionnaires. The researchers discarded 75 questionnaires for incompleteness. Due to this, the study analysis was done based on the response of 571 study participants. Proportionately stratified sampling technique was employed to determine the number of respondents across study sites, gender and age. Simple random sampling was used to recruit participants from each study sites. Besides, eight core government stakeholders in the different level and 28 leprosy patients were also selected by using available sampling technique for interview purpose.

\section{Variables}

The dependent variables of this study were community knowledge, belief and attitude towards leprosy patients. The independent variables were sociodemographic characteristics including sex, age, marital Status, educational status, religion and average monthly income.

\section{Data Collection Instruments}

Questionnaires were used to assess the knowledge, belief and attitude of the community towards leprosy patients. These questionnaires were adapted from instruments used by Subramaniam [17] and later modified by Tesema, et al. [18]. Ultimately the questionnaire has four sections where the first section collects data on students' demographic characteristics. This includes sex, age, marital Status, educational status, religion and average monthly income. The second part included eight items to assess the knowledge of community members towards leprosy patients. Also, section three was about the belief of the community towards leprosy and it consists 25 items. The items in this section examine about the cause (11 items), transmission (11 items) and treatment (4 items) of leprosy. Finally, there were 13 items that examine the attitude of the community towards leprosy.

\section{Pilot Test}

The pilot study was conducted in Ambo town, West Shewa Zone, Oromia Region, Ethiopia, by taking 75 community members randomly. Before collecting the final data, the tools were translated into Amharic and Afan Oromo language. The translation consistencies of the instruments were also examined by three language experts from Ambo University. Face validity of the English, Amharic and Afan Oromo language version was assessed by two psychologists from Ambo University. The face validity of the measuring instrument was determined by giving the questionnaires to experts in the department of psychology. The experts made corrections and suggestions which were taken into consideration while producing the final draft of the questionnaires. Based on the comments of the experts, changes were made in the wording of four belief items and two attitude items. In the pilot study, the reliabilities of the tools were found to be 0.911, 0.924 and 0.874 for knowledge, belief and attitude questionnaires respectively. The consensus of the experts was that the instruments measure what it purports to measure and was therefore adjudged adequate for the study. These tools were adjudged high enough for the instrument usability.

\section{Data Collection Procedures}

The respondents were instructed to complete the questionnaires by giving a response to every item of questions. To collect the data for the study, four supervisors were dispatched in which one supervisor for each study site were assigned. The role of supervisors was to train data collectors, oversee participant recruitment and data collection and checking and controlling data quality. A total of 16 data collectors (four for each study sites) with at least a diploma level training mainly in the social sciences were recruited. Half-day training was provided for the data collectors on the purpose of the study, the contents of the data collection instruments, ethical matters, and on how to recruit and approach participants. The data- collection process was closely followed-up by the supervisors.

\section{Data Analysis}

Descriptive statistics including percentages, mean and standard deviation were used to assess the knowledge, belief and attitude of the community towards leprosy patients. Also, ANOVA and independent sample t-test were used to examine if there was any statistically significant difference in community knowledge and attitude across their demographic variables. Point biserial correlation coefficient was also employed to assess the relationship between community knowledge and attitude. All data were analyzed using Statistical Package for Social Science (SPSS) for window version 20.

\section{Ethical Considerations}

Oral as well as written informed consent was secured from the respondents. In addition, written permission was obtained from the respective officials of the institutions and organizations where the respondents were recruited based on an official request letter issued by Ambo University. 


\section{Results and Discussion}

\section{Demographic Characteristics of the Respondents}

As can be seen from Table 1, out of 571 respondents, 316 (55.3\%) were males, and 255 (44.7\%) were female respondents. Most of the respondent's age 268 (46.93\%) ranges between 19-26 years old, followed by 182 (31.87\%) respondents whose age ranges from 27-39 years old, 108 (18.91\%) were adolescence whose ages ranged from 13-18 years old and 17 (2.97\%) were respondents whose age were 40 years old\& Above. The mean age of the respondents was 27.24 (SD =7.996) where the minimum and maximum ages are 17 and 48 respectively. With respect to marital status, 308 (53.9\%),
$232(40.63 \%)$ and 31 (5.42\%) respondents were married, single and divorced respectively. Also, regarding to educational status, out of all respondents, $213(40.45 \%)$, 116 (20.31\%), 106 (18.56\%) 78 (13.66\%), 30 (5.25\%) and $28(4.9 \%)$ had found to be illiterates, 5-8 graders, 1-4 graders, 9-12 graders, diploma holder and degree holder \& above respondents respectively. Furthermore, with regard to the religion, out of all respondents, most $396(69.4 \%)$ had found to be orthodox, followed by protestant 137 (24\%) and Waqefeta 38 (6.7\%).Finally, with regard to respondents' income, $156(27.32 \%)$ of respondents' income were considered as lower income group. Majority of them 398 (67.9\%) were perceived as middle-income groups followed by the least 17 (2.97\%) were higher income groups.

\begin{tabular}{|c|c|c|c|}
\hline Demographic Variable & Categories & Frequency & Percentile \\
\hline \multirow{2}{*}{ Sex } & Male & 316 & 55.3 \\
\hline & Female & 255 & 44.7 \\
\hline \multirow{6}{*}{ Age } & $13-18$ years old & 108 & 18.91 \\
\hline & 19-26 years old & 268 & 46.93 \\
\hline & 27-39 years old & 182 & 31.87 \\
\hline & 40years\& Above old & 17 & 2.97 \\
\hline & Mean SD & Minimum & Maximum \\
\hline & 27.247 .996 & 17 & 48 \\
\hline \multirow{3}{*}{ Marital Status } & Married & 308 & 53.9 \\
\hline & Single & 232 & 40.63 \\
\hline & Divorced & 31 & 5.42 \\
\hline \multirow{6}{*}{ Educational Status } & Illiterate & 213 & 40.45 \\
\hline & Grade 1-4 & 106 & 18.56 \\
\hline & Grade 5-8 & 116 & 20.31 \\
\hline & Grade $9-12$ & 78 & 13.66 \\
\hline & College diploma & 30 & 5.25 \\
\hline & Degree and above & 28 & 4.9 \\
\hline \multirow{3}{*}{ Religion } & Orthodox & 396 & 69.4 \\
\hline & Protestant & 137 & 24 \\
\hline & Waqefeta & 38 & 6.7 \\
\hline \multirow{3}{*}{ Average monthly income } & Lower (less than 1500 birr) & 156 & 27.32 \\
\hline & Middle (1501-4500 birr) & 398 & 69.7 \\
\hline & Higher (greater than 4501 birr) & 17 & 2.97 \\
\hline
\end{tabular}

Table 1: Socio-demographic characteristic of the respondents.

\section{Community Knowledge towards Leprosy}

The overall knowledge score was derived by the sum of the respondents' responses to questions on the cause, symptom, transmission, curability and treatment of leprosy. A score of one was assigned for every correct response and a score of zero assigned to each wrong and 'don't know' responses. The score on the knowledge of the symptoms of leprosy was obtained by summing up the responses of the respondents. Each correct answer had 
one point. Respondents who correctly cited five or more symptoms of leprosy were categorized as having high knowledge. Accordingly, it was found that, overall, only $118(20.6 \%)$ of the respondents had high level of knowledge on leprosy followed by 333(58.31\%) medium level of knowledge on leprosy and the remaining 120 $(21 \%)$ had low level knowledge on leprosy.

As can be shown from Table 2, out of 571 respondents, when the respondents were asked about leprosy, 336 $(58.8 \%)$ of the respondents believed that leprosy could spread easily. However, 235 (42.2\%) of respondents reflect the opinion that it was not. About 141 (24.7\%) held the concept that leprosy could be cured. Also, 220
(38.5\%) of respondents detained misunderstand that leprosy causes skin irritation or itchiness. Besides, 511 (89.5\%) of respondents knew that leprosy could present as skin patches, but the remaining 60 (10.5) of respondents failed to decide whether leprosy could present as skin patches or not. Hence, 393 (68.8\%) of respondents knew that leprosy could present as nodules. More than half of the respondents 393 (68.8\%) were aware that a loss of sensation could be a symptom of leprosy while 196 (34.3\%) also knew of the deformities and disfigurement associated with leprosy. Results also revealed that $10.5-48.2 \%$ of the respondents were unsure of the various symptoms of leprosy.

\begin{tabular}{|c|c|c|c|c|c|c|c|}
\hline \multirow{2}{*}{$\mathbf{s} / \mathbf{n}$} & \multicolumn{2}{|c|}{ Item } & \multicolumn{2}{c|}{ Disagree } & \multicolumn{2}{c|}{ Agree } & \multicolumn{2}{c|}{ I don't know } \\
\cline { 2 - 8 } & & $\mathbf{N o}$ & $\mathbf{9}$ & $\mathbf{F}$ & $\mathbf{\%}$ & $\mathbf{f}$ & $\mathbf{\%}$ \\
\hline 1 & Leprosy can spread easily & 336 & 58.8 & 78 & 13.7 & 157 & 27.5 \\
\hline 2 & Leprosy is curable & 352 & 61.6 & 141 & 24.7 & 78 & 13.7 \\
\hline 3 & Leprosy causes skin irritation or itchiness & 100 & 17.5 & 351 & 61.5 & 120 & 21 \\
\hline 4 & Leprosy can present as skin patches & - & - & 511 & 89.5 & 60 & 10.5 \\
\hline 5 & Leprosy can present as nodules & 60 & 10.5 & 393 & 68.8 & 118 & 20.7 \\
\hline 6 & Leprosy can present as loss of sensation & 80 & 14 & 393 & 68.8 & 98 & 17.2 \\
\hline 7 & Leprosy patients always end up with deformities & 100 & 17.5 & 196 & 34.3 & 275 & 48.2 \\
\hline 8 & Leprosy can lead to deformities or disfigurement & 40 & 7 & 531 & 93 & - & - \\
\hline
\end{tabular}

Table 2: Knowledge of respondents on leprosy in Gindeberet Woreda.

\section{Belief of the Community towards Leprosy}

The beliefs held by the respondents with regard to the causation and transmission of leprosy in descending order of prevalence. The beliefs listed as options in the questionnaire were identified during the review of relevant literature. This study identified many beliefs harbored by the respondents with regard to the cause of leprosy.

As can be seen from Table 3, out of 571 respondents, $263(48.7 \%)$ of the respondents correctly believed that leprosy was caused by germs. However, $116(20.3 \%)$ and $177(31 \%)$ of the respondents, respectively, said that leprosy was not caused by germs or did not know whether it was due to germs. Moreover, 431 (75.5\%) of respondents believed that leprosy occurs due to vitamin deficiency. However, 140 (24.5\%) of respondents said that leprosy is not due to vitamin deficiency. Hence, 413 (72.3\%) of respondents said that leprosy can be caused by unclean environment. Conversely, 158 (27.7\%) of respondents believed that leprosy cannot be caused by unclean environment. 355 (62.2\%) of respondents believed that leprosy occurs due to impure blood. 333 (58.3\%) of respondents said that did not know whether leprosy can be caused by eating too much cooling food. However, $238(41.7 \%)$ of respondents believed that leprosy cannot be caused by eating too much cooling food. A hereditary origin was stated as the cause $(48.1 \%)$ of leprosy. Immoral conduct was believed to be a cause by $34.5 \%$ of the respondents while only $14 \% 10.5 \%$ and $10.5 \%$ believed that leprosy was a punishment for sins or due to curse, witchcraft or evil spirits and a punishment for our sins/sins of parents or grand-parents respectively. 


\section{Nursing \& Healthcare International Journal}

\begin{tabular}{|c|c|c|c|c|c|c|c|}
\hline \multirow{2}{*}{$\begin{array}{l}\text { Belief of the community } \\
\text { towards }\end{array}$} & \multirow{2}{*}{ Items } & \multicolumn{2}{|c|}{ Disagree } & \multicolumn{2}{|c|}{ Agree } & \multicolumn{2}{|c|}{ I don't know } \\
\hline & & No & $\%$ & No & $\%$ & No & $\%$ \\
\hline \multirow{10}{*}{ Causes of leprosy } & Unclean environment & 158 & 27.7 & 100 & 17.5 & 313 & 54.8 \\
\hline & Eating too much 'cooling' food & 238 & 41.7 & - & - & 333 & 58.3 \\
\hline & $\begin{array}{l}\text { Punishment for our sins/sins of parents } \\
\text { or grand-parents }\end{array}$ & 431 & 75.5 & 60 & 10.5 & 80 & 14 \\
\hline & Impure blood & 216 & 37.8 & 100 & 17.5 & 255 & 44.7 \\
\hline & Curse/ punishment by God & 411 & 72 & 80 & 14 & 80 & 14 \\
\hline & Witchcraft/ evil spirits & 431 & 75.5 & 60 & 10.5 & 80 & 14 \\
\hline & Hereditary & 296 & 51.8 & 160 & 28 & 115 & 20.1 \\
\hline & Immoral conduct & 374 & 65.5 & 40 & 7 & 157 & 27.5 \\
\hline & Vitamin deficiency & 140 & 24.5 & 60 & 10.5 & 371 & 65 \\
\hline & Germs & 116 & 20.3 & 263 & 48.7 & 177 & 31 \\
\hline \multirow{11}{*}{$\begin{array}{c}\text { Means of transmission of } \\
\text { leprosy }\end{array}$} & Air & 391 & 68.5 & 20 & 3.5 & 160 & 28 \\
\hline & Contaminated soil & 313 & 54.8 & 40 & 7 & 218 & 38.2 \\
\hline & Bathing in a river & 351 & 61.5 & 20 & 3.5 & 200 & 35 \\
\hline & Insects & 391 & 68.5 & 60 & 10.5 & 120 & 21 \\
\hline & Sexual contact with leprosy patients & 371 & 65 & 80 & 14 & 120 & 21 \\
\hline & Skin contact & 80 & 14 & 217 & 38 & 274 & 48 \\
\hline & Sitting close to the leprosy patients & 471 & 82.5 & 20 & 3.5 & 80 & 14 \\
\hline & $\begin{array}{l}\text { Eating food together with leprosy } \\
\text { patients }\end{array}$ & 296 & 51.8 & 100 & 17.5 & 175 & 30.6 \\
\hline & Shaking hands with leprosy patients & 431 & 75.5 & 80 & 14 & 60 & 10.5 \\
\hline & $\begin{array}{l}\text { Sharing personal items such as towel, } \\
\text { toothbrush etc. with leprosy patients }\end{array}$ & 431 & 75.5 & 40 & 7 & 100 & 17.5 \\
\hline & Passed from mother to infant & 291 & 51 & 200 & 51 & 80 & 14 \\
\hline \multirow{4}{*}{ Treatment of leprosy } & pharmaceutical drugs against leprosy & 40 & 7 & 431 & 75.5 & 100 & 17.5 \\
\hline & medicinal herbs & 236 & 41.3 & 40 & 7 & 295 & 51.5 \\
\hline & religious rituals & 371 & 65 & 120 & 21 & 80 & 14 \\
\hline & isolated from others during treatment & 314 & 55 & 117 & 20.5 & 140 & 24.5 \\
\hline
\end{tabular}

Table 3: Distribution of Respondents on Beliefs Regarding the Cause, Means of Transmission and Treatment of Leprosy.

As can be revealed in Table 3, among all 571 respondents, more than half of respondents $200(51 \%)$ stated incorrectly that leprosy could be transmitted from mother to infant. Also, 217 (38\%) of respondents believed that leprosy could also be transmitted by personal contact such as sharing personal items including towels and toothbrushes. However, many respondents were aware of the fact that it could be transmitted by casual contact like sitting close to the leprosy patients (3.5\%), shaking hands (14\%), and sharing personal items $(7 \%)$ with a patient. Almost $(10.5 \%)$ and $(3.5 \%)$ of respondents reported that leprosy was transmitted by insects and air respectively.
Concurrently, many respondents were aware of the fact that it could not be transmitted by sexual contact with leprosy patients (65\%), bathing in a river $(61.5 \%)$, contaminated soil (54.8\%) and eating food together with leprosy patients $(51.8 \%)$.

As shown from Table 3, out of the total 571 respondents, 431 (75.5\%) correctly reported that leprosy could be treated with anti-leprosy drugs recommended for the treatment of leprosy whereas the others said it could not be treated 40 (7\%) or were unsure 100 (17.5\%) about treatment with anti-leprosy drugs. While $40(7 \%)$ 
also believed in medicinal herbs as a cure of leprosy, the role religious rituals in the treatment of leprosy were also stated by $120(21 \%)$ of the respondents. Moreover, 117 $(20.5 \%)$ of respondents incorrectly believed that leprosy patients should be isolated from others during treatment.

\section{Attitudes of the Community towards Leprosy}

The respondents' overall attitude score that reflected their attitudes towards having physical and/or social contact with a leprosy patient was determined by the sum of their responses to the selected statements. Hence, the respondents who agreed or strongly agreed with all statements reporting positive attitudes or acceptance of leprosy patients were categorized as having positive attitude or acceptance towards a person with leprosy (score of 32 - 52). The respondents who disagreed or strongly disagreed or responded neutral to these statements were categorized as having negative or stigmatizing attitudes (score of 31 or less) towards a patient with leprosy. Due to this, it was found that, out of 571 community members, one third of respondents 220 (38.5\%) had positive attitude towards leprosy patients and $351(61.4 \%)$ had negative attitude towards leprosy patients.
Thirteen questions were asked from the respondents to assess their attitudes towards leprosy patients. The results in Table 4 showed that, overall, the attitude of the community in this study towards leprosy patients was in general downbeat. Most of the respondents had negative attitude towards leprosy patients. About 456 (79.8\%) of the study subjects report that they did not sit with leprosy patients in public conveyance, $404(70.7 \%)$ of them report that they would avoid leprosy patients to shake their hands, 417 (73\%) did not share food from the same plate with leprosy patients, 351 (61.4\%) of respondents did not want to buy food from leprosy patients, 259 $(45.3 \%)$ of respondents did not agree to do work in the same place with leprosy patients, 348 (60.9\%) of respondents were not voluntary to house together with leprosy patients, $382(66.9 \%)$ of respondents did not want to be friends with a leprosy patient, 267 (46.7\%) said that they did not allow their children to play with child of leprosy patients, 359 (69.1\%) of respondents did not allow the leprosy patients to use public transport, 75 $(13.1 \%)$ of them report that they would not allow the leprosy patients to attend public functions, 437 (76.5\%) of respondents said that it is difficult for leprosy patients to get married. Many 459 (80.3\%) also said that they would feel sorry or pity for the patient and 504 (88.2\%) said they were willing to help a patient in need.

\begin{tabular}{|c|c|c|c|c|c|c|}
\hline \multirow{2}{*}{$\mathbf{s} / \mathbf{n}$} & Item & $\begin{array}{c}\text { Strongly } \\
\text { Disagree }\end{array}$ & Disagree & Undecided & Agree & $\begin{array}{c}\text { Strongly } \\
\text { Agree }\end{array}$ \\
\cline { 3 - 6 } & No (\%) & No (\%) & No (\%) & No (\%) & No (\%) \\
\hline $\mathbf{1}$ & I will sit beside a leprosy patient & $288(50.4)$ & $152(26.6)$ & $16(2.8)$ & $31(5.4)$ & $84(14.7)$ \\
\hline $\mathbf{2}$ & $\begin{array}{c}\text { I am willing to shake hands with leprosy } \\
\text { patient }\end{array}$ & $228(39.9)$ & $131(22.9)$ & $45(7.9)$ & $109(19.1)$ & $58(10.2)$ \\
\hline $\mathbf{3}$ & $\begin{array}{c}\text { I am willing to share food with a leprosy } \\
\text { patient }\end{array}$ & $148(25.9)$ & $41(7.2)$ & $228(39.9)$ & $55(9.6)$ & $99(17.3)$ \\
\hline $\mathbf{4}$ & I would buy food from a leprosy patient & $91(15.9)$ & $33(5.8)$ & $227(39.8)$ & $136(23.8)$ & $84(14.7)$ \\
\hline $\mathbf{5}$ & $\begin{array}{c}\text { I am prepared to work in the same } \\
\text { environment with a leprosy patient }\end{array}$ & $71(12.4)$ & $35(6.1)$ & $153(26.8)$ & $214(37.5)$ & $98(17.2)$ \\
\hline $\mathbf{6}$ & I will house a leprosy patient & $133(23.3)$ & $10(1.8)$ & $205(35.9)$ & $171(29.9)$ & $52(9.1)$ \\
\hline $\mathbf{7}$ & I will be friends with a leprosy patient & $112(19.6)$ & $66(11.6)$ & $204(35.7)$ & $132(23.1)$ & $57(10.0)$ \\
\hline $\mathbf{8}$ & $\begin{array}{c}\text { I will allow my children to play with a } \\
\text { child of a leprosy patient }\end{array}$ & $109(19.1)$ & $88(15.4)$ & $70(12.5)$ & $250(43.8)$ & $54(9.5)$ \\
\hline $\mathbf{9}$ & $\begin{array}{c}\text { Leprosy patients should be allowed to use } \\
\text { public transport }\end{array}$ & $39(6.8)$ & $315(55.2)$ & $41(7.2)$ & $140(24.5)$ & $36(6.3)$ \\
\hline $\mathbf{1 0}$ & $\begin{array}{c}\text { Leprosy patients should be allowed to } \\
\text { attend public functions }\end{array}$ & $14(2.5)$ & $21(3.7)$ & $40(7.0)$ & $161(28.2)$ & $335(58.7)$ \\
\hline $\mathbf{1 1}$ & $\begin{array}{c}\text { I will allow a cured leprosy patient to } \\
\text { marry a member of my family }\end{array}$ & $123(21.5)$ & $228(39.9)$ & $86(15.1)$ & $65(11.4)$ & $69(12.1)$ \\
\hline $\mathbf{1 2}$ & I will feel sorry or pity for a leprosy patient & $6(1.1)$ & $54(9.5)$ & $52(9.1)$ & $158(27.7)$ & $301(52.7)$ \\
\hline $\mathbf{1 3}$ & I will help a leprosy patient if necessary & $8(1.4)$ & $39(6.8)$ & $20(3.5)$ & $362(63.4)$ & $142(24.9)$ \\
\hline
\end{tabular}

Table 4: Distribution of the attitudes of the respondents towards leprosy patients. 


\section{Nursing \& Healthcare International Journal}

\section{Differences in Community Knowledge towards Leprosy by Demographic Variables}

(Table 5) informs us that the number of male respondents who score above the mean $(81 \%)$ is higher than the number of female respondents who score above the mean $(76.5 \%)$. This implies that more males than females had significantly higher knowledge regarding the symptoms of leprosy. And these differences in proportions were statistically significant $\left(\chi^{2}=15.437, d f=\right.$ $1, \mathrm{p}<0.05)$. Moreover, religion of the respondents had statistically significant effect on knowledge $\left(\chi^{2}=41.167\right.$, $d f=1, \mathrm{p}<0.05)$. Correspondingly, higher proportion of protestant respondents had higher knowledge of the symptoms of leprosy when compared Orthodox and waquaffeta. Regarding to educational status of respondents in Table 7, illiterate respondents appeared to have lower knowledge of the symptoms of leprosy as compared to 1-4 graders, 5-8 graders, 9-12 graders, diploma holders and degree \& above holders. This difference in the levels of knowledge was statistically significant $\left(\chi^{2}=179.405, d f=1, \mathrm{p}<0.05\right)$.Table 7 also shows us that the knowledge of symptoms of leprosy increased significantly with increasing age of the respondents $\left(\chi^{2}=7.267, d f=1, \mathrm{p}<0.05\right)$. Besides, the analysis by average monthly income of the respondents also showed a statistically significant effect on knowledge of community members $\left(\chi^{2}=4.984, d f=1, \mathrm{p}>0.05\right)$. Correspondingly, respondents with higher monthly income had a higher knowledge than those respondents with lower and middle income groups towards the symptoms of leprosy. However, the difference was not statistically significant.

\begin{tabular}{|c|c|c|c|c|c|c|c|}
\hline \multirow{4}{*}{ Variable } & \multirow{4}{*}{ Category } & \multirow{4}{*}{ Mean (SD) } & \multicolumn{3}{|c|}{ Level of knowledge } & \multirow{4}{*}{$\chi^{2}$} & \multirow{4}{*}{ P value } \\
\hline & & & Lower & Medium $n=356$ & Higher & & \\
\hline & & & $n=120$ & 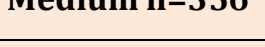 & $n=95$ & & \\
\hline & & & $\mathrm{N}(\%)$ & $\mathrm{N}(\%)$ & $\mathrm{N}(\%)$ & & \\
\hline \multirow{2}{*}{ Sex } & Male & $11.98(1.638)$ & $60(19 \%)$ & $218(69 \%)$ & $38(12 \%)$ & \multirow{2}{*}{15.437} & \multirow{2}{*}{0} \\
\hline & Female & $11.65(2.241)$ & $60(23.5 \%)$ & $138(54.1 \%)$ & $57(22.4 \%)$ & & \\
\hline \multirow{3}{*}{ Religion } & Orthodox & 11.64(1.939) & $100(25.2 \%)$ & $236(59.6 \%)$ & $60(15.2 \%)$ & \multirow{3}{*}{41.167} & \multirow{3}{*}{0} \\
\hline & Protestant & $11.81(1.541)$ & $20(14.6 \%)$ & $100(73 \%)$ & $17(12.4 \%)$ & & \\
\hline & Waaqeffataa & $13.29(2.024)$ & - & $20(52.6)$ & $18(47.4 \%)$ & & \\
\hline \multirow{6}{*}{ Educational status } & Illiterate & $10.59(1.984)$ & $71(44.9 \%)$ & $79(50 \%)$ & $8(5.1 \%)$ & \multirow{6}{*}{-179.41} & \multirow{6}{*}{0} \\
\hline & Grade $1-4$ & $12.64(1.508)$ & $12(8.9 \%)$ & $94(69.6 \%)$ & $29(21.5 \%)$ & & \\
\hline & Grade 5-8 & $12.54(1.464)$ & $7(5.2 \%)$ & $85(63.4 \%)$ & $42(31.3 \%)$ & & \\
\hline & Grade 9-12 & $11.74(1.092)$ & $11(12.9 \%)$ & $70(82.4 \%)$ & $4(4.7 \%)$ & & \\
\hline & Diploma & $13.00(0.471)$ & - & $26(92.9 \%)$ & $2(7.1 \%)$ & & \\
\hline & Degree \&above & $10.77(3.412)$ & $19(61.3 \%)$ & $2(6.5 \%)$ & $10(5.2 \%)$ & & \\
\hline \multirow{4}{*}{ Age } & 13-18 years & $11.65(1.887)$ & $15(23.4 \%)$ & $42(65.6 \%)$ & $7(10.9 \%)$ & \multirow{4}{*}{7.267} & \multirow{4}{*}{0.007} \\
\hline & 19-26 years & $11.79(1.992)$ & $66(21.9 \%)$ & $180(59.8 \%)$ & $55(18.3 \%)$ & & \\
\hline & 27-39 years & $12.01(1.865)$ & $34(17.8 \%)$ & $124(64.9 \%)$ & $33(17.3 \%)$ & & \\
\hline & 40years\& Above & $11.13(1.767)$ & $5(33.3 \%)$ & $10(66.7 \%)$ & - & & \\
\hline \multirow{3}{*}{ Income } & Lower & $11.93(1.745)$ & $28(18.3 \%)$ & $100(65.4 \%)$ & $25(16.3 \%)$ & \multirow{3}{*}{4.984} & \multirow{3}{*}{0.289} \\
\hline & Medium & $11.75(2.002)$ & $91(22.7 \%)$ & $245(61.1 \%)$ & $65(16.2 \%)$ & & \\
\hline & Higher & $12.82(1.740)$ & $1(5.9 \%)$ & $11(64.7 \%)$ & $5(29.4 \%)$ & & \\
\hline
\end{tabular}

Table 5: Association between selected socio demographic characteristics of the community and knowledge level on leprosy $(\mathrm{n}=571)$.

\section{Comparison of Attitude of the Community towards Leprosy across Demographic Variable}

As can be designated in Table 6, the independent sample t-test result shows that there was no statistically significant mean difference in attitude of the community towards leprosy between male and female respondents $(\mathrm{t}$ $(569)=-1.821, p>0.05)$. Here, the mean score of attitude towards leprosy for female respondents $(M=33.83$,
$\mathrm{SD}=8.957)$ was higher than male respondents $(\mathrm{M}=32.15$, $\mathrm{SD}=12.383)$.

\begin{tabular}{|c|c|c|c|c|c|c|}
\hline Variable & Category & $\mathbf{N}$ & $\mathbf{M}$ & $\mathbf{S D}$ & t-value & $\mathbf{p}$-value \\
\hline \multirow{2}{*}{ Sex } & Male & 316 & 32.15 & 12.38 & \multirow{2}{*}{-1.821} & \multirow{2}{*}{0.069} \\
\cline { 2 - 6 } & Female & 255 & 33.83 & 8.957 & & \\
\hline
\end{tabular}

Table 6: Mean Difference between sex of respondent on Attitude of the community on leprosy 
As can be seen from Table 7, educational status of respondents had the statistically significant effect (F $(5,565)=61.053, p<0.05)$ on attitude towards leprosy. Along with this, the mean attitude score towards leprosy of illiterates $(\mathrm{M}=24.75, \mathrm{SD}=10.604)$ was lower than 1-4 graders $(M=34.62, S D=7.704), 5-8$ graders $(M=38.28$, $\mathrm{SD}=8.490)$ and $9-12$ graders $(\mathrm{M}=39.73, \mathrm{SD}=6.638)$. This result indicates that the higher the educational status of the respondent, the positive attitude will be. In the same fashion, the Bonferroni post hoc result demonstrated that highly significant leprosy attitude score mean differences were reported among respondents with illiterate respondents $(\mathrm{p}<0.05)$ than $1-4$ graders $(\mathrm{p}<0.05), 5-8$ graders $(p<0.05), 9-12$ graders $(p<0.05)$, diploma holder $(\mathrm{p}<0.05)$ and degree holder \&above $(\mathrm{p}<0.05)$. However, insignificant leprosy attitude score differences were obtained between 5-8 graders as compared to 9-12 graders ( $p>0.05)$, diploma holder $(\mathrm{p}>0.05)$ and degree holder \& above $(\mathrm{p}>0.05)$.

\begin{tabular}{|c|c|c|c|c|c|c|}
\hline Variable & Category & $\mathbf{N}$ & $\mathbf{M}$ & SD & $\mathbf{F}$ & p-value \\
\hline \multirow{6}{*}{ Educational Status } & Illiterate & 213 & 24.75 & 10.6 & \multirow{6}{*}{61.05} & \multirow{6}{*}{0} \\
\hline & Grade 1-4 & 106 & 34.62 & 7.704 & & \\
\hline & Grade 5-8 & 116 & 38.28 & 8.49 & & \\
\hline & Grade 9-12 & 78 & 39.73 & 6.638 & & \\
\hline & Diploma & 30 & 39.26 & 5.999 & & \\
\hline & Degree and above & 28 & 40.35 & 8.722 & & \\
\hline \multirow{3}{*}{ Marital Status } & Single & 308 & 31.7 & 12.09 & \multirow{3}{*}{9.946} & \multirow{3}{*}{0} \\
\hline & Married & 232 & 33.51 & 9.598 & & \\
\hline & Divorced & 31 & 40.26 & 4.968 & & \\
\hline \multirow{3}{*}{ Income } & Lower income & 156 & 33.39 & 12 & \multirow{3}{*}{0.304} & \multirow{3}{*}{0.738} \\
\hline & Middle income & 398 & 32.67 & 10.63 & & \\
\hline & Higher income & 17 & 33.88 & 10.79 & & \\
\hline \multirow{4}{*}{ Age } & 17-26 years old & 108 & 23.37 & 10.35 & \multirow{4}{*}{41.16} & \multirow{4}{*}{0} \\
\hline & 27-39 years old & 268 & 35.17 & 10.1 & & \\
\hline & $40-59$ years old & 182 & 35.37 & 9.466 & & \\
\hline & 60 years and above & 17 & 30.92 & 11.11 & & \\
\hline
\end{tabular}

Table 7: ANOVA of the effect of respondents' age, educational status, religion and income on Attitude towards leprosy.

In addition, Table 7 also illustrated that the mean score of attitude towards leprosy for single respondents $(M=31.70, S D=12.087)$ were lower than married $(M=$ 33.51, $\mathrm{SD}=9.598)$ and divorced respondents $(M=40.26$, $\mathrm{SD}=4.968)$ and the difference was statistically significant $(\mathrm{F}(2,568)=9.946, \mathrm{p}<0.05)$. Correspondingly, the Bonferroni post hoc result revealed that there was a highly significant attitude towards leprosy score mean difference among for single respondents as compared to divorced respondents $(\mathrm{p}<0.05)$. However, insignificant attitude towards leprosy mean differences were obtained among single respondents as compared to married respondents ( $p>0.05)$. Moreover, table 9 also shows us that average monthly income of the respondents had insignificant effect on attitude towards leprosy $(\mathrm{F}(2,568)$ $=0.304, \mathrm{p}>0.05$ ). Consistently, the mean attitude towards leprosy score of respondents with higher income $(M=33.88, S D=10.787)$ was higher than respondents with middle income $(\mathrm{M}=32.67, \mathrm{SD}=10.627)$ and lower income $(\mathrm{M}=33.39, \mathrm{SD}=11.998)$.
As can be seen from Table 7 , the age of respondents had a statistically significant effect $(\mathrm{F}(3,567)=41.160$, $\mathrm{p}<0.05$ ) on attitude towards leprosy. In the same fashion, the Bonferroni post hoc result demonstrated that highly significant attitude towards leprosy score mean differences were reported among respondents whose age ranges from $17-26$ years old $(\mathrm{p}<0.05)$ than respondents whose age ranges from 27-39 years old $(p<0.05)$ and respondents whose age ranges from 40-59 years old ( $\mathrm{p}<$ 0.05). The mean attitude towards leprosy score of respondents whose age ranges from 17-26 years old $(\mathrm{M}=23.37, \mathrm{SD}=10.348)$ was lower than respondents whose age ranges from 27-39 years old $(M=35.17$, $\mathrm{SD}=10.096$ ), respondents whose age ranges from 40-59 years old $(M=35.37, S D=9.466)$ and respondents whose age ranges from 60 years old \& above $(M=30.92$, $\mathrm{SD}=11.109$ ). 


\section{Nursing \& Healthcare International Journal}

\section{Correlation between Knowledge and Attitudes of the Community towards Leprosy Patients}

As can be shown from Table 8, the result of point biserial correlation coefficient shows that strong positive correlation were observed between the knowledge and attitudes of the community towards leprosy patients $(r=$ $0.752, \mathrm{p}<0.05$ ). This implies that as the knowledge of the community towards leprosy improves, the attitude of the community becomes more likely positive. Due to this, higher knowledge is very essential for positive attitude of the community towards leprosy patients.

\begin{tabular}{|c|c|c|}
\hline \multirow{2}{*}{ Variable } & Attitude Score & \multirow{2}{*}{ P value } \\
\cline { 2 - 3 } & point bi-serial $(r)$ & \\
\hline Knowledge score & 0.725 & 0.016 \\
\hline
\end{tabular}

Table 8: Correlation between knowledge and attitudes of the community towards Leprosy patients.

*Significant at the 0.05 level

\section{Discussion}

The purpose of the present study was to assess the knowledge, belief and attitude of the community towards leprosy patients in Gindeberet woreda. The finding of the present study showed that only $118(20.6 \%)$ of the respondents had high level of knowledge on leprosy. This result was supported with that of Nisar, et al. [19] from Karachi, Pakistan and Barkataki [3] from Uttar Pradesh, India reported that community members had poor knowledge about leprosy. Similarly, Tesema, et al. [18] also found that only $19.3 \%$ of the respondents had high level of knowledge on leprosy. However, the present study result yields inconsistence with previous research findings of Raju [20] from Andhra Pradesh and Stephen in a rural Tamil Nadu who found that community members had a high knowledge levels. In addition, Mohite, et al. [21] reported that $78.94 \%$ community members had overall a good knowledge about leprosy and this difference in results could be due to high literacy level, sound economic conditions and proper implementation of health services at the corner of community by district leprosy control unit in the present study area as well as the nature of sample size.

This finding revealed that more than half of the respondents believed that leprosy could spread easily and only $24.7 \%$ held the concept that leprosy could be cured. These results was consistent with previous studies conducted by Chen [9], Gerochi [22] and van de Weg, et al. [12] in Asia and Africa who found that significant number of the respondents believed that leprosy spreads easily. Similar fears of contagion have been documented in studies from Mangalore, India [7] and Tekle-Haimanot, et al. [11] in Ethiopia which showed that $53-64 \%$ of the population were of the belief that leprosy was highly infectious.

In this study, one third of respondents detained misunderstand that leprosy causes skin irritation or itchiness. Besides, most of respondents knew that leprosy could present as skin patches, Hence, more than of respondents knew that leprosy could present as nodules. More than half of the respondents were aware that a loss of sensation could be a symptom of leprosy while one third also knew of the deformities and disfigurement associated with leprosy. Results also revealed that 10.5$48.2 \%$ of the respondents were unsure of the various symptoms of leprosy. Correspondingly, this result was consistent with study in Nepal that shows that $95 \%$ of the leprosy patients known by the community have observable signs like wounds, swellings and deformed feet or hands [9]. Hence, skin patches and loss of sensation as symptoms of leprosy were known to $73 \%$ of the family members [23]. Also, study done in Guadalajara showed that $64 \%$ knew presence of skin lesions as a sign of leprosy, and $60 \%$ knew that a microbe causes the disease. Similarly, majority of respondents had some knowledge of leprosy but no one knew early signs or symptoms or where to get proper diagnosis and treatment [24]. However, only $15 \%$ of the communities were aware of the early signs of the disease and $54 \%$ of them felt that leprosy is contagious [7]. Similar findings have been found in a study by Bekri, et al. [6] conducted in Ethiopia, which showed that misconceptions about the symptoms, low awareness of modern treatment, and the influence of traditional healers or community leaders lead to delay in seeking treatment for leprosy.

In the present study with regard community belief towards the cause of leprosy, respondents believed that leprosy occurs due to vitamin deficiency (75.5\%), unclean environment (72.3\%), impure blood (62.2\%) and hereditary origin $(48.1 \%)$. However, nearly half of the respondents correctly believed that leprosy was caused by germs. This result was consistent with that of Subramaniam [17] who reported that majority of respondents in Singapore believed that germs can cause leprosy. Also, this study was also similar with that of Stephen, et al. [23] who found that $37 \%$ of family members of leprosy patients were aware that leprosy is caused by a germ. This findings was also in agreement with various prior works that include attribution of leprosy to bad blood, $[3,19,24]$ and the misplaced notion 


\section{Nursing \& Healthcare International Journal}

of extreme contagiousness by casual contact and heritability $[3,25]$. Very few people among the community know that leprosy is caused by a germ (8\%) [7]. A high knowledge level did not necessarily generate positive attitudes towards leprosy but there were situations in which it helps to have positive attitudes. However, the result of this finding was not pertinent with a study of Tekle-Haimanot, et al. [11] in Ethiopia who found that a significant number of people believed that leprosy was hereditary (48\%) and contagious (53\%). Also, a study conducted by Shetty, et al. [7] in India revealed that very few $(7 \%)$ knew that leprosy was caused by germs. In addition, Pal, et al. [8] study revealed that, overall, only $8.5 \%$ knew the cause of the disease. It was also contradictory from a study conducted by Chen [9] who claimed that most Chinese believed that sexual relations with prostitutes ( $41.2 \%)$ and heredity (32.5\%) caused leprosy whereas the Iban community believed that heredity (41.8\%) was the predominant cause. This result also yields inconsistent with a study done in Ethiopia in which more than half of respondents believed that leprosy is the result of curse and calamity, while only $13 \%$ of the respondents understand the causes of the disease correctly [26]. A study done in India which shows $37 \%$ of the participants believe that leprosy is caused by bacteria [23] and skin to skin contact with leprosy patient $45.7 \%$ [27]. Study in Mexico showed that $60 \%$ of the respondents said that leprosy is caused by microbes [28], infection (50\%) [3] and very few 8\% said that it is caused by germs [7].

The result of the present study showed that more than half of respondents stated incorrectly that leprosy could be transmitted from mother to infant. Also, more than one third of respondents believed that leprosy could also be transmitted by personal contact such as sharing personal items including towels and toothbrushes. This result was inconsistent with a study in India which revealed that respondents believed that leprosy was transmitted through sharing food and drinks, utensils, contact with the leprosy patient's sweat, mosquito or insect bites and sexual contact with a person with leprosy [27]. Also studies in China revealed that the disease has been transmitted during sexual intercourse with prostitutes [29]. However, Mankar, et al. [25] found that $84.31 \%$ of persons with leprosy did not know the mode of transmission.

Regarding to the treatment of leprosy, more than two third of respondents correctly reported that leprosy could be treated with anti-leprosy drugs recommended for the treatment of leprosy. This result was reliable with that of Shetty [7] who found that most of the respondents (79\%) said it is necessary to attend hospital for leprosy treatment. However, research in Myanmar found that community members believed that all leprosy affected persons would inevitably end up with some deformity [30], which increased the dread of the disease. In India, the more severe the disability, the greater was the level of stigma [31].

The result of the present study showed that most of the respondents had negative attitude towards leprosy patients that was supported by Chen [9]; Tekle-Haimanot, et al. [11] and Hilary [32] who have reported largely negative community attitudes towards leprosy patients. Only $17 \%$ of a community in Ethiopia were willing to work together with a leprosy patient [11] while as few as 1 to $25 \%$ of the respondents in an Indian study were willing to share food with a leprosy patient [20]. Some other studies have also reported avoidance of a leprosy patient because of the fear of being infected or opposed to even casual contact with leprosy patients [33,34]. In addition, similar with the present finding, previous studies found that the attitude of the general public towards individuals with leprosy was negative [10,22,3538] . A study conducted by Nisar from Karachi, Pakistan noticed very poor attitude towards leprosy in fishing community in which $49.8 \%$ of respondents dislike to buy foods from leprosy patients and $47.1 \%$ of respondents said it was difficult to find work for leprosy patients [19]. Other study in Guyana indicated that prejudice was still present in the wider community and a significant minority believed that patients should be kept apart from other people [39]. But the finding was different from [20] from Andhra Pradesh that community members had a high knowledge levels as well as had a positive attitude towards leprosy.

In this study, more males than females had significantly higher knowledge regarding the symptoms of leprosy. And these differences in proportions were statistically significant which was supported by various studies $[14,18,39,40]$.

The result of the present study shows that religion of the respondents had statistically significant effect on knowledge. Correspondingly, higher proportion of protestant respondents had higher knowledge of the symptoms of leprosy when compared Orthodox and Waquaffeta. This result was not consistence with that of Iyor, [40]) who found that Christian religion followers had high knowledge of the symptoms of leprosy. And with study done in Tanzania where Muslim religion was associated with lower knowledge, stigmatizing attitude and beliefs towards leprosy [14]. 


\section{Nursing \& Healthcare International Journal}

Regarding to educational status of respondents, illiterate respondents appeared to have lower knowledge of the symptoms of leprosy as compared to 1-4 graders, 58 graders, 9-12 graders, diploma holders and degree \& above holders. This difference in the levels of knowledge was statistically significant. The present finding was in accordance with that of Raj, et al. [41] in India who reported that the literate and younger age groups had better awareness of the leprosy disease. In addition, this finding was also pertinent with various previous studies $[18,21,38,39]$ who found that education of community members were significantly associated with knowledge about leprosy. Also, study in India confirmed the significant association between literacy and level of knowledge towards leprosy among the community [11].

In this study, the knowledge towards the symptoms of leprosy increased significantly with increasing age of the respondents which is supported by Mohite, et al. [21]. Furthermore, Raj, et al. [41] claimed that younger age groups had better awareness of the leprosy disease.

In the present study, age, marital status and educational status had a statistically significant effect on attitude of the community members. This result yield consistent results with a research conducted by Mohite \& Mohite [21] who found that age and education were significantly associated with positive attitude towards leprosy. Study conducted by Tesema [18] from Ethiopia also reported similar findings i.e. age and education was significantly associated with positive attitude in community members. However, as per the study of Iyor [39], the association of educational level and attitude towards people with leprosy was not significant. This indicated that although people may have the knowledge towards leprosy it may not guarantee that they could have positive attitude towards leprosy. Also, study in India confirmed the significant association between literacy and attitude of the community towards leprosy [11].

The result of the present study shows that strong positive correlation was observed between the knowledge and attitudes of the community towards leprosy patients. This implies that as the knowledge of the community towards leprosy improves, the attitude of the community becomes more likely positive. Similar findings have also been reported by Raju [20] from Andhra Pradesh in which community members had a high knowledge levels as well as had a positive attitude towards leprosy through indicating that good knowledge and a positive attitude towards disease goes in hand and hand. Besides, this study result was also similar with Mohite, et al. [21] who described that the strong correlation between knowledge and attitude of community towards leprosy. A study conducted by Subramaniam [17] from Singapore has also been reported that an increased knowledge score were significantly correlated with a positive attitude. However; low correlation between knowledge and attitude among the community with relation to leprosy was reported by Mutatkar [42]. In addition, Raju, et al. [20] in Orrisa, India showed that respondents had a good knowledge about leprosy but had a negative attitude towards disease. Similar findings have also been reported by Stephen et al [23]. Misconceptions regarding the cause of leprosy are one of the most compelling factors that influence a community's health seeking behaviors and determine their attitudes towards those affected by the disease $[10,43,44]$.

\section{Conclusion}

Regarding the knowledge about more than one third of the participants had poor level knowledge on leprosy whereas more than half of respondents had negative attitude towards leprosy. More specifically, nearly half of the respondents correctly believed that leprosy was caused by germs. However, $75.5 \%-48.1 \%$ of respondents were attributed vitamin deficiency, unclean environment, impure blood, eating too much cooling food and hereditary as the causes of leprosy respectively while only $14 \%-10.5 \%$ believed that leprosy was a punishment for sins/curse and evil spirits respectively. Hence, nearly half of respondents stated that leprosy could be transmitted from mother to infant and personal contact. Also, one fourth of the respondents correctly reported that leprosy could be treated with anti-leprosy drugs. In fact, more than one third did not want to sit with leprosy patients. Besides, most of the respondents were not able to list down the cardinal signs of leprosy correctly and most of the respondents didn't know the patho-physiology of disability in leprosy. In this study, the level of leprosy knowledge was associated with the sex, age, educational status, and religion of respondents. Moreover, sex, religion, age and educational status had statistically significant effect on respondents' attitude towards leprosy. In addition, strong positive correlation was observed between the knowledge and attitudes of the community towards leprosy patients.

\section{Recommendation}

Based on the result and conclusion of the study, all concerned bodies, including psychologists, public health workers, and religious leaders shall provide continuous training on leprosy to enhance the community knowledge. There is a need to educate the community in order to 


\section{Nursing \& Healthcare International Journal}

alleviate the stigma and promote positive attitude towards leprosy. Awareness raising programs to remove misconceptions related to cause and spread and treatment of the disease shall be improved. All concerned governmental, non-governmental and civil society stakeholders shall work hand in hand to improve health education for the community. Besides, Gindeberet Woreda administrators in collaboration with government and non- government organizations shall prepare seminar, symposia and panel discussions for the community to raise awareness regarding the cause, symptom, transmission and treatment of leprosy. Additionally, the regional government in collaboration with researchers, experts, and counselors shall develop the structured system that enables them sustainably carry out critical goals relation to lower Knowledge and poor attitude towards leprosy.

\section{References}

1. Steven D (2012) Leprosy Causes, Symptoms and Treatment. E Medicine health.

2. Sileshi B (2015) Leprosy in Ethiopia: Epidemiological trends from 2000 - 2011. Advances in Life Science and Health 2(1): 31-44.

3. Barkataki P, Kumar S, Rao PSS (2006) Knowledge of and attitudes to leprosy among patients and community members: a comparative study in Uttar Pradesh, India. Lepr Rev 77(1): 62-68.

4. WHO (2000) A Guide to Eliminate Leprosy as a Public Health Problem, World health Organization.

5. Briden A, Maguire E (2003) An assessment of knowledge and attitude towards leprosy/Hansen's disease amongst healthcare workers in Guyana. Lepr Rev 74: 154-162.

6. Bekri W, Gebre S, Mengiste A, Saunderson PR, Zewge S (1998) Delay in presentation and start of treatment in leprosy patients: a case-control study of disabled and non disabled patients in three different settings in Ethiopia.

7. Shetty JN, Shivaswamy SS, Shirwadkar PS (1985) Knowledge, attitude and practices of the community and patients regarding leprosy in Mangalore-a study. Indian J Lepr 57(3): 613-619.

8. Pal S, Girdhar BA (1985) A study of knowledge of disease among leprosy patients and attitude of community towards them. Indian J Lepr 57(3): 620623.

9. Chen P (1986) Human behavioral research applied to the leprosy control programme of Sarawak, Malaysia. Southeast Asian J Trop Med Public Health 17(3): 421426.

10. Kumaresan JA and Maganu ET (1994) Socio-cultural dimensions of leprosy in North Western Botswana. Social Sci Med 39(4): 537-541.

11. Tekle Haimanot $\mathrm{R}$, Forsgren $\mathrm{L}$, Gebre-Mariam A, Abebe M, Holmgren G, et al. (1992) Attitudes of rural people in central Ethiopia towards leprosy and a brief comparison with observation with epilepsy. Lepr Rev 63(2): 157-168.

12. Van de Weg N, Post EB, Lucassen R, et al. (1998) Explanatory models and help seeking behaviour of leprosy patients in Adamawa state, Nigeria. Leprosy Rev 69: 382-389.

13. Kumar RP, Keystone JS, Christian M, Jesudasan K (1991) Transmission of health information on leprosy from children to their families: another approach to health education. Lepr Rev 62(1): 58-64.

14. Jacob MS, Amar D, Christopher A, Keystone JS (1994) Transmission of health information on leprosy from children to their families in an urban centre. Lepr Rev 65: 272-278.

15. Desalegn T (2014) The Pleasing Unspoken Voices: The Unpredictable Incidents of life and Strive to Withstand. Ethiopian National Association of Persons Affected by Leprosy. Addis Ababa, Ethiopia.

16. Yonas GM (2014) A Study on the Psycho-Social and Economic Situation of Leprosy Patients in Ethiopia: The Case of Admitted Patients at Alert center; Thesis: Addis Ababa University; Addis Ababa, Ethiopia.

17. Subramaniam P (2003) A study on community knowledge, beliefs and attitudes on leprosy in

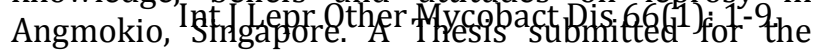
Degree of Master of Science. Department of Community, Occupational \& Family Medicine National University of Singapore.

18. Tesema AA, Berio M (2015) Assessment of knowledge and attitude of community on leprosy patients in Kuyera Town, west Arsi Zone, Oroma 


\section{Nursing \& Healthcare International Journal}

19. Nisar N, Khan IA, Qadri MH, et al. (2007) Knowledge attitude and Practices about leprosy in a fishing community in Karachi Pakistan. Pak J Med Sci 23: 936-240.

20. Raju MS, Kopparty SN (1995) Impact of knowledge of leprosy on the attitude towards leprosy patients: A community study. Ind J Leprosy 67(3): 259-271.

21. Mohite RV, Mohite VR (2016) Knowledge and Attitude of Indian Rural Community towards Leprosy after Post Elimination Phase: A Survey from Karad Block, India. Ntl J Community Med 7(10): 797-801.

22. Gerochi LN (1986) Knowledge, beliefs and attitudes on leprosy in Iloilo City, Philippines. Southeast Asian J Trop Med Public Health 17(3): 422-426.

23. Stephen T, Selvaraj I, Gopalakrishnan S (2014) Assessment of Knowledge, Attitude and Practice about leprosy among patients and their families in a rural community in Tamil Nadu. National Journal of Research in Community Medicine 3(2): 164-170.

24. John AS, Rao PS (2009) Awareness and attitudes towards leprosy in urban slums of Kolkata, India. Indian J Lepr 81(3): 135-140.

25. Mankar MJ, Joshi SM, Velankar DH, Mhatre RK, Nalgundwar AN (2011) A Comparative study of the quality of life, knowledge, attitude and belief about leprosy disease among leprosy patients and community members in Shantivan leprosy rehabilitation centre, Nere, Maharashtra, India. J Glob Infect Dis 3(4): 378-382.

26. ENAELP (2003) Baseline Survey Report: on Persons Affected by Leprosy and their Families in GunchireGuraghe Zone, SNNPR. Unpublished Survey Report.

27. Singh S, Sinha AK, Banerjee BG, Jaswal N (2012) Knowledge, Beliefs and Perception of Leprosy. Asia Pacific Disability Rehabilitation Journal 1(1): 67-75.

28. Graciano Machuca O, Velarde de la Cruz EE, Ramírez Dueñas MG, Alvarado Navarro A (2013) University students' knowledge and attitudes towards leprosy. J Infect Dev Ctries 7(9): 658-664.

29. Ramakrishina J, Weiss G (2001) Stigma interventions and research for interventional health. Dept of public health and epidemology, Swiss Tropical Institute.
30. Myint T, Thet AT, Htoon MT, Win M (1992) A comparative KAP study of leprosy patients and members of the community in Hlaing and Laung-Lon townships. Indian J Lepr 64(3): 313-324.

31. PrabhakaraRao V, Rao IR, Palande DD (2000) Socioeconomic rehabilitation programmes of LEPRA India - Methodology, results and application of needs based socio-economic evaluation. Lepr Rev 71(4): 466-471.

32. Hilary C (2000) Comparative study of knowledge, attitudes and practices towards leprosy in an intervention and a control group of the community in Bangladesh. Unpublished Master's Dissertation, National University of Singapore.

33. De Stigter DH, De GeusL, Heynders ML (2000) Leprosy: between acceptance and segregation. Community behaviour towards persons affected by leprosy in eastern Nepal. Leprosy Rev 71(4): 492498.

34. Withington SG, Joha S, Baird D, Brink M, Brink J (2003) Assessing socio-economic factors in relation to stigmatisation, impairment status and selection for socio-economic rehabilitation: a 1-year cohort of new leprosy cases in north Bangladesh. Leprosy Rev 74(2): 120-132.

35. Croft RP, Croft RA (1999) Knowledge, attitude and practice regarding Leprosy and Tuberculosis in Bangladesh. Leprosy Rev 70(1): 34-42.

36. Qubati Y, Kubati AS (1997) Dermatologists combat leprosy in Yemen. Int J Dermatol 36(12): 920-922.

37. Rajaratnam J, Abel R, Arumai M (1999) Is knowledge of leprosy adequate among teachers? A Comparative study. Leprosy Review 70: 28-33.

38. Suite M, Gittens C (1992) Attitudes towards leprosy in the outpatient population of dermatology clinics in Trinidad. Leprosy Review 63(2): 151-156.

39. Wong M, Subramaniam P (2002) Socio-cultural issues in leprosy control and management. Asia Pacific Disability Rehabilitation Journal 13(2): 85-94.

40. Iyor FT (2005) Knowledge and Attitude of Nigerian Physiotherapy Students about Leprosy. Asia Pacific Disability Rehabilitation Journal 16(1): 85-92. 
41. Raj V, Garg BR, Lal S (1981) Knowledge about leprosy among leprosy patients. Leprosy in India 53(2): 226230.

42. Mutatkar RK, Ranade MG (1986) Evaluation of health education in leprosy control program, methodological consideration. South East Asian J Tropical Medicine and Public Health 77: 437-441.
43. Cook A (1982) An Urban community thought about leprosy. A survey in Guyana. Leprosy Review 53(4): 285-296.

44. Van den Broek J, O’Donoghue J, Ishengoma A, Masao H, Mbega M (1998) Evaluation of a sustained 7 year health education campaign on leprosy in Rufiji District in Tanzania. Leprosy Review 69(1): 57-74. 